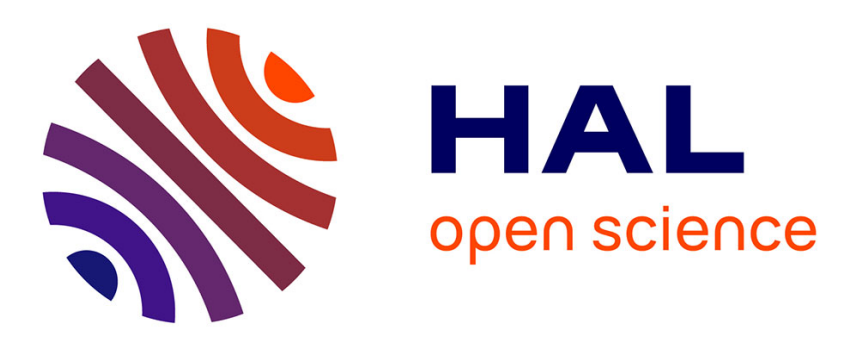

\title{
Charge transport modelling in electron-beam irradiated dielectrics: a model for polyethylene
}

Séverine Le Roy, Fulbert Baudoin, Virginie Griseri, C Laurent, G. Teyssedre

\section{To cite this version:}

Séverine Le Roy, Fulbert Baudoin, Virginie Griseri, C Laurent, G. Teyssedre. Charge transport modelling in electron-beam irradiated dielectrics: a model for polyethylene. Journal of Physics D: Applied Physics, 2010, 43 (31), pp.315402. 10.1088/0022-3727/43/31/315402 . hal-00569666

\section{HAL Id: hal-00569666 https://hal.science/hal-00569666}

Submitted on 25 Feb 2011

HAL is a multi-disciplinary open access archive for the deposit and dissemination of scientific research documents, whether they are published or not. The documents may come from teaching and research institutions in France or abroad, or from public or private research centers.
L'archive ouverte pluridisciplinaire HAL, est destinée au dépôt et à la diffusion de documents scientifiques de niveau recherche, publiés ou non, émanant des établissements d'enseignement et de recherche français ou étrangers, des laboratoires publics ou privés. 


\title{
Charge Transport Modelling in Electron-Beam Irradiated Dielectrics: Model for Polyethylene
}

\author{
S Le Roy ${ }^{1,2}$, F Baudoin ${ }^{1}$, V Griseri ${ }^{1}$, C Laurent ${ }^{1,2}$ and G Teyssedre ${ }^{1,2}$ \\ ${ }^{1}$ Université de Toulouse ; UPS, INPT; LAPLACE (Laboratoire Plasma et Conversion \\ d'Energie) ; \\ 118 route de Narbonne, F-31062 Toulouse cedex 9, France. \\ ${ }^{2}$ CNRS ; LAPLACE ; F-31062 Toulouse, France. \\ E-mail: severine.leroy@laplace.univ-tlse.fr
}

\begin{abstract}
This paper proposes a numerical model for describing charge accumulation in electron-beam irradiated low density polyethylene. The model is bipolar, and based on a previous model dedicated to space charge accumulation in solid dielectrics under electrical stress. It encompasses the generation of positive and negative charges due to the electron beam and their transport in the insulation. A sensitivity analysis of the model to parameters specific to electron beam irradiation is performed in order to understand the impact of each process on the space charge distribution. At last, a direct comparison between time dependent space charge distribution issued from the model and from measurements is performed. The transport parameters used for the simulations are the same as those optimized for transportation in polyethylene under an external electric field giving a robustness in the modelling approach because of the constrains on fitting parameters that must comply to a set of experimental results.
\end{abstract}

PACS Numbers: $72.20 \mathrm{Ht}, 72.20 \mathrm{Jv}$ 


\section{Introduction}

Solid dielectrics used as thermal blanket on geostationary satellites are submitted to the flow of several types of charged particles, and particularly to electrons. These materials can accumulate charges, building up the potential inside the dielectric, meaning a potential difference between different parts of the satellite. Electrostatic $\underline{\text { Surface }}$ Discharge (ESD) can occur, leading to possible damages of the electronics of the satellite [1]. In order to prevent such ESD to happen, it is necessary to understand the dynamics of the charge transport in solid dielectrics used in space environment. A number of studies have been carried out in this domain. Some are experimental, measuring the surface potential of the irradiated samples, the current flow during irradiation [2] and the space charge distribution after irradiation [3]. Recently, two original set-ups [4-5] to measure space charge distribution in electronbeam irradiated samples have been developed on the basis of the Pulsed Electro-Acoustic (PEA) method. With these experimental tools, it is now possible to observe the dynamic of charging and discharging in electron-beam irradiated materials. On the other hand, a number of works on theoretical background and simulation has been done in order to understand and reproduce the behaviour of charge in electron beam irradiated polymers [6-9].

Our very aim is to develop space charge modelling in electron beam irradiated materials in nonstationary conditions through an approach that closely associates experiment and numerical simulation. Within the first part of this paper, we briefly review the state-of-the-art on modelling charge transport in synthetic insulations under electron beam irradiation in order to establish the position of our approach. Then, we describe the proposed model, which has been adapted from a previous one [10] developed for space charge conduction in a Low Density Polyethylene (LDPE) under DC stress. The same set of transport parameters has been used though extra parameters are necessary to describe the effect of electron irradiation. A sensitivity analysis of the model to these parameters is proposed, and the model is then parameterized to reproduce the main features observed on space charge measurements obtained on irradiated LDPE sample using the 'open PEA' method where the irradiated surface is at a floating potential.

\section{Theoretical background and evidence of bipolar processes}

A large number of models have been developed to study charge transport in solid dielectrics under electron beam irradiation. They can be classified in two categories, being function of the way the interaction of primary electrons with the solid dielectric is described:

- The interaction can be described by introducing a radiation-induced conductivity (RIC), which decays after irradiation. The description is macroscopic, and only electrons are considered. Several versions of the model are available in [11-13]. The advantages of this description are its simplicity, and the possibility to experimentally determine most of the parameters.

- The interaction can be described by taking explicitly into account the generation of carrier pairs. The description is more microscopic, and the model is bipolar $[6,9,14,15]$. Transport of positive and negative charges due to electric field can be considered, as well as recombination of positive and negative carriers. These models accurately describe the dynamic of charges in polymeric materials, but the drawbacks remain the number of parameters and the fact that their value is difficult to determine experimentally.

Considering experiments, Perrin et al [16] have developed two new Pulsed Electro-Acoustic set-ups in order to measure the space charge distribution in solid dielectrics during irradiation: an 'open circuit' PEA where the irradiated face of the sample is at a floating potential, and a 'short-circuit' PEA where the sample is provided with two electrodes being grounded. Evidences have been given on the presence of positive charges during electron beam irradiation on a $500 \mu \mathrm{m}$ thick LDPE $[5,16]$. We recall these evidences in the following:

- Figure 1 (taken from [5]) shows the space charge distribution for different irradiation times (0-36 min), measured on a $500 \mu \mathrm{m}$ thick LDPE with the 'open circuit' PEA under irradiation with an electron beam of $200 \mathrm{keV}$ energy and a flux of $50 \mathrm{pA} . \mathrm{cm}^{-2}$. After 24 min of irradiation, a positive charge density is observed at the vicinity of the ground electrode, which can be differentiated from the image charge. It has been interpreted as resulting from the injection of positive charges at the ground electrode driven by the field generated by the implanted electrons. 


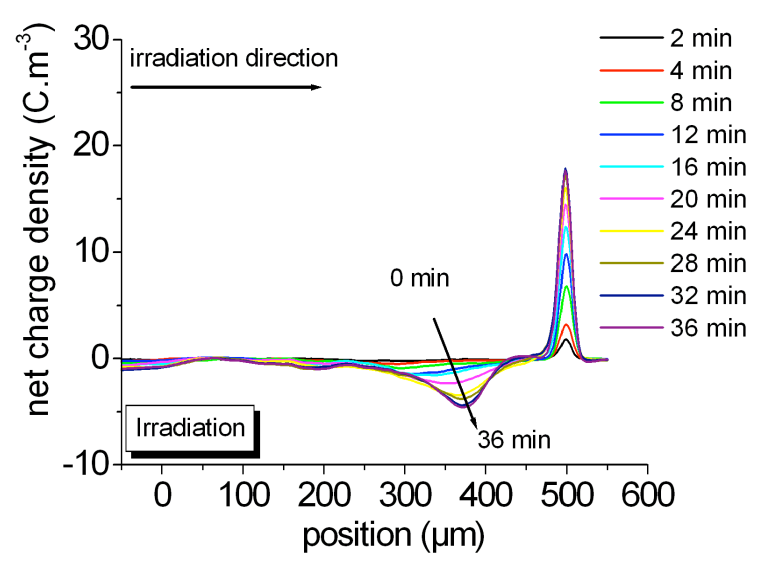

a)

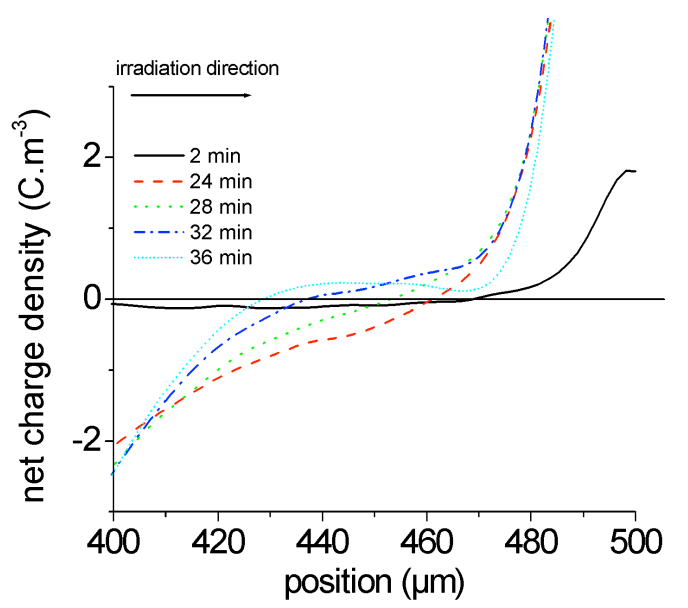

b)

Figure 1: a) Experimental space charge profiles measured for a $500 \mu \mathrm{m}$ LDPE in 'Open-circuit' configuration during $36 \mathrm{~min}$ of irradiation with a $200 \mathrm{keV}$ electron beam. b) Zoom of the region 400-500 $\mu \mathrm{m}$ where positive charges are observed (replotted from [5] with the permission of the authors).

- Space charge measurements performed by the same team [16] on a $500 \mu \mathrm{m}$ thick LDPE with the 'short circuit' PEA (figure 2) during relaxation also show the appearance of positive charges at $\sim 325$ $\mu \mathrm{m}$ from the irradiated face. These positive charges appear after $30 \mathrm{~min}$ of relaxation, and their amount increases with relaxation time. The most probable process for the appearance of this net positive charge is the transport of electrons towards both electrodes, concomitantly with the transport of positive charges from the irradiated region towards the middle of the dielectric, both being driven by the space charge field.

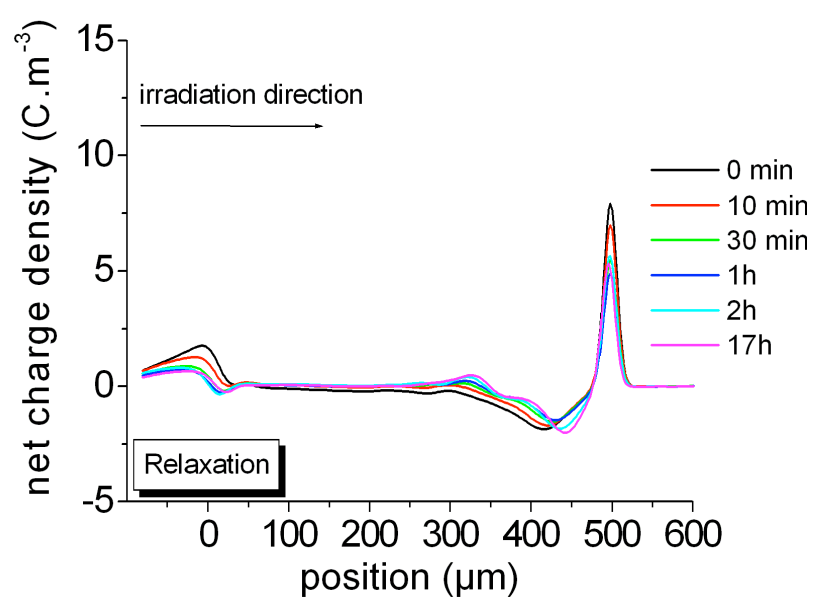

a)

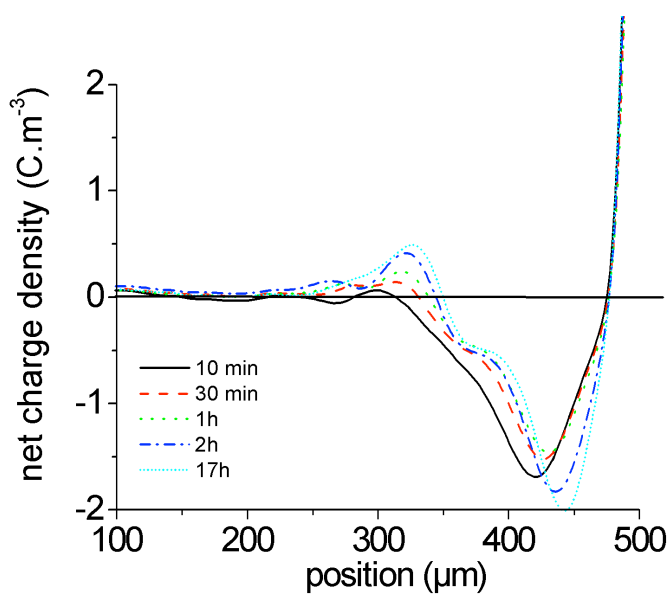

b)

Figure 2: a) Experimental space charge profiles measured for a $500 \mu \mathrm{m}$ LDPE in 'Short-circuit' configuration during relaxation following an irradiation of $36 \mathrm{~min}$ with a $200 \mathrm{keV}$ electron beam. b) zoom of the region 100-

$500 \mu \mathrm{m}$ where positive charges are observed (replotted from [16] with the permission of the authors).

These experimental results reveal the necessity to consider positive and negative charges for the simulation of charge transport in irradiated materials. For these reasons we choose a bipolar model including all the features pertaining to charge injection, trapping and transport for both types of charge.

\section{Model description}

\subsection{Model Equations}

The bipolar model developed is derived from [10]. It is one-dimensional, function of the position in the dielectric, and based on the scheme presented in figure 3. One transport level is considered for each type of carriers where the drift of the particle is described by using an effective mobility. We use a constant mobility in this work albeit other expressions can also be used, e.g. field-assisted hopping 
mobility [17]. Deep trapping is described using a unique level of deep traps for each kind of carriers from where charges can escape by thermal activation. Recombination processes involving mobile and trapped carriers of different sign can be taken into account. Irradiation is described following the socalled 'Generation-Recombination' model (GR) in reference [7], i.e. it takes into account the generation of electron/hole pairs due to energy loss of primary electrons as well as the electron deposition in the irradiated zone, and the recombination of these charges.

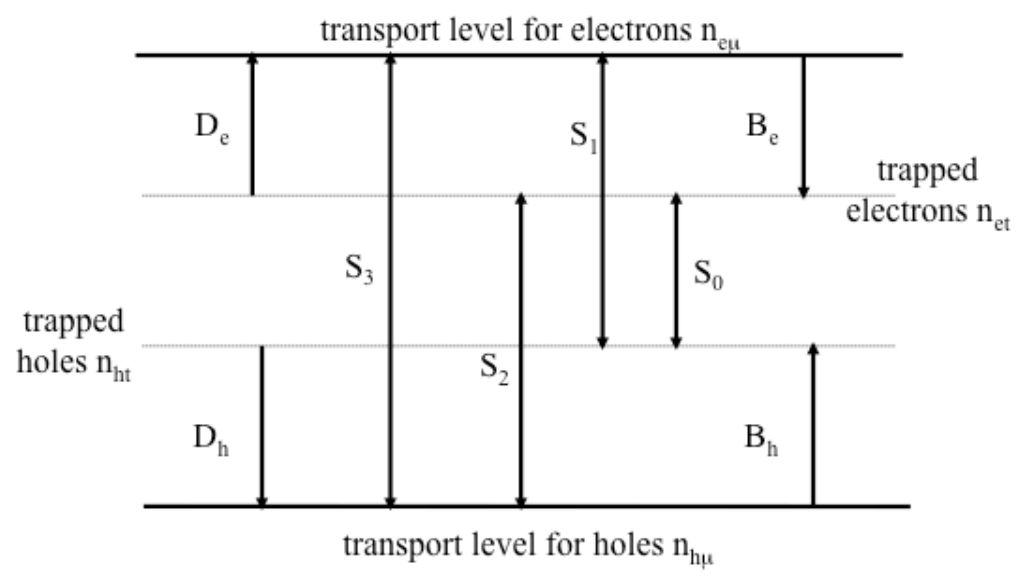

Figure 3: Schematic representation of the conduction and trapping model for solid dielectrics. $S_{i}$ are recombination coefficients, $\mathrm{n}_{\mathrm{e},}, \mathrm{n}_{\mathrm{et}}, \mathrm{n}_{\mathrm{ht}}, \mathrm{n}_{\mathrm{hu}}$ are mobile and trapped electron and hole densities; $\mathrm{B}_{\mathrm{e}}$ and $\mathrm{B}_{\mathrm{h}}$ are electron and hole trapping coefficients, $D_{e}$ and $D_{h}$ are the detrapping coefficients, function of an activation energy.

The equations to solve are of the form, neglecting diffusion:

$$
\begin{array}{ll}
j_{e, h}(x, t)=n_{e, h}(x, t) \cdot \mu_{e, h} \cdot E(x, t) & \text { Transport equation } \\
\frac{\partial E(x, t)}{\partial x}=\frac{\rho(x, t)}{\varepsilon_{0} \varepsilon_{r}} & \text { Poisson's equation } \\
\frac{\partial n_{e, h}(x, t)}{\partial t}+\frac{\partial j_{e, h}(x, t)}{\partial x}=s_{i}(x, t) & \text { Continuity equation }
\end{array}
$$

where the indexes $e$ and $h$ refer to the type of charge, i.e. electron or hole and $\mathrm{x}$ is the direction perpendicular to the electrodes; $\mathrm{j}_{\mathrm{e}, \mathrm{h}}$ is the transport current density for each kind of carriers, $\mathrm{n}$ is the charge density. $\mu_{\mathrm{e}, \mathrm{h}}$ refers to the mobility, and $\mathrm{E}$ is the electric field. $\rho$ is the net charge density, $\varepsilon_{0}$ the vacuum permittivity, $\varepsilon_{r}$ the dielectric permittivity and $\mathrm{t}$ is the time. The boundary conditions for Poisson's equation are the following:

- at the irradiated face, $\mathrm{E}(0, \mathrm{t})=0$, as we consider that the electrode is at infinity. Preliminary results, taking into account the electric field in the air gap show that there is no real difference in the space charge profiles, the electric field being really small in the air gap compared to the one due to charge deposition. We will then keep this value as a first approximation;

- $\quad$ at the ground electrode, $\mathrm{V}(\mathrm{L}, \mathrm{t})=0$.

$\mathrm{s}_{\mathrm{i}}$ are the source terms, which encompass the changes in local density by processes other than transport (irradiation-induced effects, trapping, detrapping, etc). They can be written, neglecting the time and space dependency of the densities:

- for mobile electrons :

$$
S_{e \mu}(x, t)=-\underbrace{\frac{\partial J_{0}(x)}{\partial x}}_{\text {electron beam }}+\underbrace{G(x)}_{\begin{array}{c}
\text { electron/hole } \\
\text { pairs generation }
\end{array}}-\underbrace{B_{e} \cdot n_{e \mu}\left(1-\frac{n_{e t}}{n_{e 0 t}}\right)}_{\text {trapping }}+\underbrace{D_{e} \cdot n_{e t}}_{\text {detrapping }}-\underbrace{S_{1} n_{e \mu} \cdot n_{h t}-S_{3} \cdot n_{e \mu} \cdot n_{h \mu}}_{\text {recombination }}
$$

- for trapped electrons:

$$
s_{e t}(x, t)=B_{e} \cdot n_{e \mu}\left(1-\frac{n_{e t}}{n_{e 0 t}}\right)-D_{e} \cdot n_{e t}-S_{0} n_{e t} \cdot n_{h t}-S_{2} \cdot n_{e t} \cdot n_{h \mu}
$$


- for mobile holes:

$$
s_{h \mu}(x, t)=\underbrace{G(x)}_{\begin{array}{c}
\text { electron/hole } \\
\text { pairs generation }
\end{array}}-\underbrace{B_{h} \cdot n_{h \mu}\left(1-\frac{n_{h t}}{n_{h 0 t}}\right)}_{\text {trapping }}+\underbrace{D_{h} \cdot n_{h t}}_{\text {detrapping }}-\underbrace{S_{2} n_{h \mu} \cdot n_{e t}-S_{3} \cdot n_{e \mu} \cdot n_{h \mu}}_{\text {recombination }}
$$

- for trapped holes:

$$
s_{h t}(x, t)=B_{h} \cdot n_{h \mu}\left(1-\frac{n_{h t}}{n_{h 0 t}}\right)-D_{h} \cdot n_{h t}-S_{0} n_{h t} \cdot n_{e t}-S_{1} \cdot n_{h \mu} \cdot n_{e \mu}
$$

$S_{0}$ to $S_{3}$ refer to the recombination coefficients (see figure 3). $G(x)$ is the electron/hole pair generation, and is of the form [7]:

$$
G(x)=G_{0} . D(x)
$$

where $\mathrm{G}_{0}$ is the electron/hole pair generation coefficient and $\mathrm{D}(\mathrm{x})$ the normalized dose rate due to the electron beam. $G(x)$ is void in the non irradiated region (NIR).

$\mathrm{J}_{0}(\mathrm{x})$ in (4) refers to the beam current density in the dielectric. Note here that once thermalized, primary electrons are considered as a source term for mobile electrons in the model. Also, carriers issued from pair generation are initially mobile.

The source terms due to irradiation (electron beam and electron/hole pair generation in (4) and (6)) disappear during the relaxation period.

Generation of positive or negative charges at the grounded electrode is possible through a modified Schottky law [18], the nature of injected carriers being function of the sign of the electric field:

$$
j_{i n j}(L, t)=A T^{2} \exp \left(\frac{-e \cdot w_{i n j}}{k_{B} T}\right)\left\{\exp \left(\frac{e}{k_{B} T} \sqrt{\frac{e \cdot E(L, t)}{4 \cdot \pi \cdot \varepsilon_{0} \cdot \varepsilon_{r}}}\right)-1\right\}
$$

where $\mathrm{A}$ is the Richardson constant, e the elementary charge, and $\mathrm{w}_{\mathrm{inj}}$ the injection barrier height. $\mathrm{k}_{\mathrm{B}}$ is the Boltzmann constant, $\mathrm{T}$ the temperature, and $\mathrm{E}(\mathrm{L}, \mathrm{t})$ the electric field at the electrode at position $\mathrm{L}$. The extraction of charges is possible at the grounded electrode, and follows an ohmic law.

\subsection{Numerical techniques}

The numerical technique for the resolution of each equation has been chosen to provide the best compromise between results accuracy and CPU time. Poisson's equation is solved using the discretization method. Continuity equation is solved by the QUICKEST scheme [19] combined with a flux limiter ULTIMATE [20]. A full description of the numerical schemes used to resolve the equations of the model is given in [21].

\section{Model behaviour and sensitivity analysis}

Though most of the parameters of the model cannot be found in the literature $\left(\mathrm{G}_{0}\right.$, trapping coefficients, recombination coefficients...), transport parameters (mobilities of electron and hole, trapping, detrapping) have already been optimized for a LDPE under electrical stress [10], and will be used in the case of electron beam irradiation. Parameters linked to processes specific to electron beam irradiation $\left(\mathrm{G}_{0}\right.$ and recombination coefficients, as part of the GR model) will be tested, to understand their role on space charge distribution. This will also simplify the final parameterization for comparison with experimental results. For sake of simplicity, study of the model sensitivity to parameters linked to the irradiation is performed with symmetrical transport parameters for positive and negative carriers as given in table 1 , unless otherwise stated.

Simulations concern experimental results obtained on a $500 \mu \mathrm{m}$ thick LDPE sample irradiated in a direction perpendicular to the sample plane by a $200 \mathrm{keV}$ electron beam with a homogeneous flux of 50 pA. $\mathrm{cm}^{-2}$ during 36 min (experimental conditions used in [5]). Measurements were performed with a PEA set-up in the "open configuration", i.e. the irradiated surface is at a floating potential. Consequently, simulations are performed in the same configuration (boundary conditions being $\mathrm{E}=0$ at the irradiated surface and $\mathrm{V}=0$ at the grounded electrode). In all the figures, irradiation comes from the left $(x=0)$ and the right electrode is grounded. Charge injection/extraction from the metallic electrode is only possible at the grounded electrode, the sign of the injected carriers being dependent upon the electric field. Other effects such as the emission of charges from the irradiated surface into the vacuum have not been considered here. 


\subsection{Electron and dose deposition}

An application code based on GEANT4 libraries [22] and dedicated to electron slow down analysis has been used to calculate the electron path length distribution as well as the dose rate deposited inside polyethylene. The code is based on multiple scattering theories (Lewis formalism) in the energy range

Table 1: Symmetrical parameterization of the bipolar model in order to test the impact of the electron/hole pair generation and recombination coefficients.

\begin{tabular}{|c|c|c|}
\hline Symbol & Value & Units \\
\hline $\begin{array}{l}\text { Trapping coefficient } \\
B_{e} \text { electrons } \\
B_{h} \text { holes }\end{array}$ & $\begin{array}{l}7.10^{-3} \\
7.10^{-3}\end{array}$ & $\begin{array}{l}\mathrm{s}^{-1} \\
\mathrm{~s}^{-1}\end{array}$ \\
\hline $\begin{array}{l}\text { Mobility } \\
\text { Electrons } \\
\text { holes }\end{array}$ & $\begin{array}{l}\text { 9. } 10^{-15} \\
\text { 9. } 10^{-15}\end{array}$ & $\begin{array}{l}m^{2} V^{-1} s^{-1} \\
m^{2} V^{-1} s^{-1}\end{array}$ \\
\hline $\begin{array}{l}\text { Deep trap density } \\
\mathrm{N}_{\text {oet }} \text { for electrons } \\
\mathrm{N}_{\text {oht }} \text { for holes }\end{array}$ & $\begin{array}{l}100 \\
100\end{array}$ & $\begin{array}{l}\mathrm{C} \mathrm{m}^{-3} \\
\mathrm{C} \mathrm{m}^{-3}\end{array}$ \\
\hline $\begin{array}{l}\text { Schottky injection barrier } \\
\mathrm{W}_{\mathrm{ei}} \text { for electrons } \\
\mathrm{W}_{\mathrm{hi}} \text { for holes }\end{array}$ & $\begin{array}{l}\infty(\text { no injection }) \\
\infty(\text { no injection }) \\
\end{array}$ & $\begin{array}{l}\mathrm{eV} \\
\mathrm{eV}\end{array}$ \\
\hline $\begin{array}{l}\text { Detrapping barrier height } \\
\mathrm{w}_{\text {tre }} \text { for electrons } \\
\mathrm{W}_{\text {trh }} \text { for holes }\end{array}$ & $\begin{array}{l}0.99 \\
0.99\end{array}$ & $\begin{array}{l}\mathrm{eV} \\
\mathrm{eV}\end{array}$ \\
\hline $\begin{array}{l}\text { Recombination coefficients } \\
S_{0}, S_{1}, S_{2}, S_{3}\end{array}$ & variable & $\mathrm{m}^{3} \cdot \mathrm{s}^{-1} \cdot \mathrm{C}^{-1}$ \\
\hline $\begin{array}{l}\text { Electron / hole pair generation coefficient } \\
\mathrm{G}_{0}\end{array}$ & variable & $\mathrm{C} \mathrm{m}^{-3} \cdot \mathrm{s}^{-1}$ \\
\hline
\end{tabular}

domain $[250 \mathrm{eV}-100 \mathrm{GeV}]$. It takes into account secondary Bremsstrahlung emission as well as gamma rays emitted near the surface. Both radiations travel deep inside the material and are able to deposit doses beyond the depth attainable by incident electrons. GEANT 4 enables to obtain the current $\mathrm{J}_{0}$ and the dose rate $\mathrm{D}$ of the incident electrons as a function of the depth in the dielectric, data necessary for the calculation of the electrons deposition and the electron / hole pairs generation ((4), (6) and (8)). It also gives an indication on the distribution of the electron density deposited by the electron beam. Calculations have been performed with 150000 particles. Values of the normalized beam current density and the normalized dose are given in figure 4 as a function of the depth in the sample. The irradiated region (IR) extents over $490 \mu \mathrm{m}$. The normalized electron density deposited by the electron beam is also given in figure 4c). It shows a maximum at $297 \mu \mathrm{m}$ from the irradiated surface.

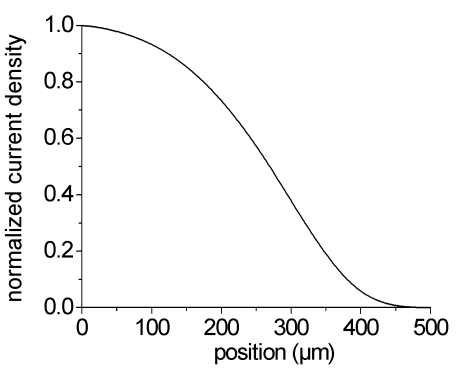

a)

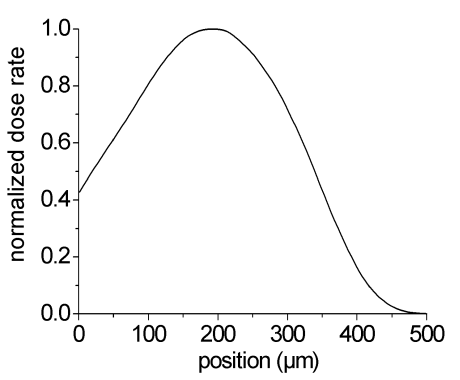

b)

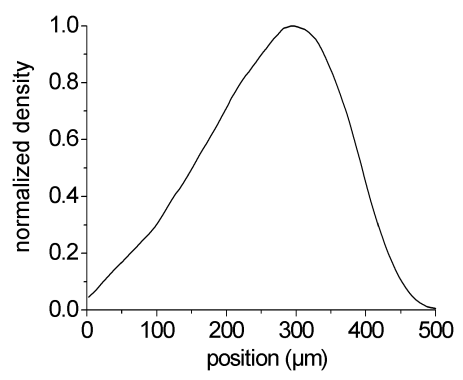

c)

Figure 4: a) normalized current density, b) normalized dose and c) normalized electron density deposited by the electron beam as a function of the position in the sample calculated by GEANT 4 for a $500 \mu \mathrm{m}$ thick LDPE irradiated by a $200 \mathrm{keV}$ electron beam, $50 \mathrm{pA} \cdot \mathrm{cm}^{-2}$. 


\subsection{Electron distribution with transport}

In a first step, only charge deposition is accounted for as charge generation mechanism, i.e. there is no injection of charges at the electrode and there is no electron / hole pairs generation $\left(\mathrm{G}_{0}\right.$ is set to 0$)$. In these conditions, only negative charges, mobile or trapped, are present in the bulk. Figure 5 shows the evolution of the charge density as a function of the irradiation time. After 2 min, one can observe a negative peak centered at $300 \mu \mathrm{m}$ from the irradiated electrode. This value is the same as the one for the electron density deposited by the beam (figure 4c), meaning that after $2 \mathrm{~min}$, the main process is charge deposition. The negative charge density increases with irradiation time and the charge peak shifts towards the ground electrode (from $300 \mu \mathrm{m}$ after 2 min to $311 \mu \mathrm{m}$ after $36 \mathrm{~min}$ ). Electrons deposited by the beam transport towards the ground electrode due to the negative value of the electric field (figure 6), changing progressively the shape of the charge distribution.

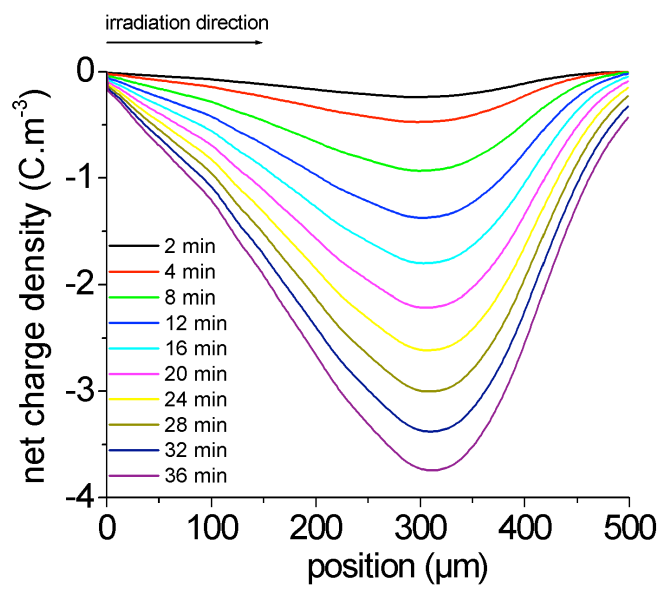

Figure 5: Simulated charge density vs. position in the dielectric for different irradiation times for a $500 \mu \mathrm{m}$ thick LDPE irradiated for $36 \mathrm{~min}$ with a $200 \mathrm{keV}$ electron beam. Simulations performed for an 'open-circuit' configuration. Parameters of the model as in table 1.

The electric field at the irradiated face is always equal to zero, while the electric field inside the dielectric increases with the irradiation time (figure 6). In these simulations, no charge injection is considered at the ground electrode. However, if injection process were taken into account, the negative value of the field would imply an injection of positive charges at this electrode.

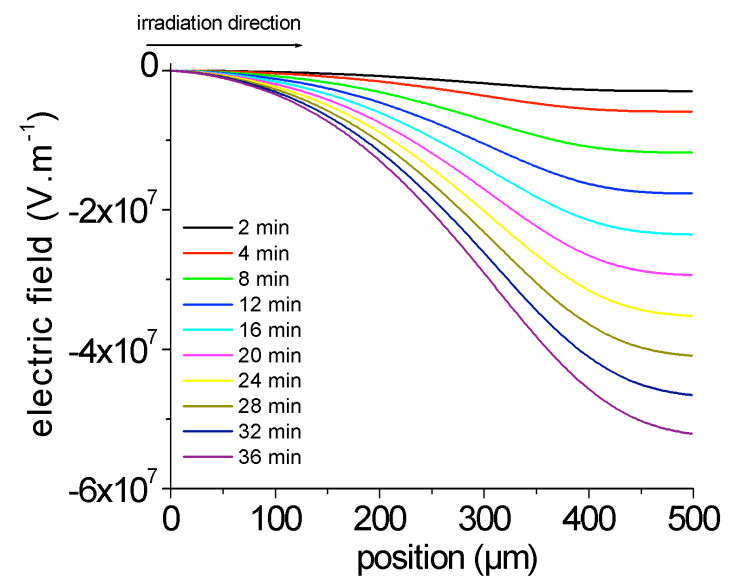

Figure 6: Simulated electric field vs. position in the dielectric for different irradiation times for a $500 \mu \mathrm{m}$ thick LDPE irradiated for 36 min with a $200 \mathrm{keV}$ electron beam. Simulations performed for an 'open-circuit' configuration. Parameters of the model as in table 1. 


\subsection{Sensitivity analysis to irradiation parameters}

\subsubsection{Electron/hole pairs generation coefficient}

Generation of electron/hole pairs due to the electron beam is function of the dose and of a coefficient $\mathrm{G}_{0}$ (8). This coefficient is difficult to determine experimentally, for the type of material under study. It has been calculated in [6] as being function of the deposited energy rate per unit area $\mathrm{W}$ :

$$
G_{0}=\frac{W \cdot e}{N \cdot E_{0} \cdot r}
$$

$e$ is the elementary charge, $\mathrm{N}$ the area under the normalized dose rate and has been calculated from figure $4 \mathrm{~b}(\mathrm{~N}=0.585)$; $\mathrm{r}$ corresponds to the irradiated region $(490 \mu \mathrm{m})$, and $E_{0}$ is the mean energy required to create a pair. We retained the value of $E_{0}=30 \mathrm{eV}$ given in [6]. If we calculate the electron/hole pairs coefficient for our experimental conditions, i.e. an electron beam flux of $50 \mathrm{pA} . \mathrm{cm}^{-}$ ${ }^{2}$ and an energy of $200 \mathrm{keV}$, we obtain $\mathrm{W}=10^{-5} \mathrm{~W} \cdot \mathrm{cm}^{-2}$ and $\mathrm{G}_{0}=10 \mathrm{C} \cdot \mathrm{m}^{-3} \cdot \mathrm{s}^{-1}$. This is however only an approximation, so we evaluated the sensitivity of the model to $G_{0}$, i.e. the way modification of this parameter influences the space charge distribution. In these simulations, injection of charges at the electrode and recombination processes have been let aside, but positive and negative charges can be trapped into deep traps and can detrap. Figure 7 shows the space charge distribution after $36 \mathrm{~min}$ of irradiation for different values of $\mathrm{G}_{0}$, with the parameters of table 1 . When $\mathrm{G}_{0}$ increases, i.e. when the generated positive and negative charge density increases in the bulk, the net charge density remains negative but the peak maximum increases and shifts towards the grounded electrode. The area under the peak would stay constant if no electrons were extracted at the ground electrode, which is clearly not the case here. It is to note that for $\mathrm{G}_{0}=5 \mathrm{C} \cdot \mathrm{m}^{-3} \cdot \mathrm{s}^{-1}$, the peak maximum reaches the ground electrode.

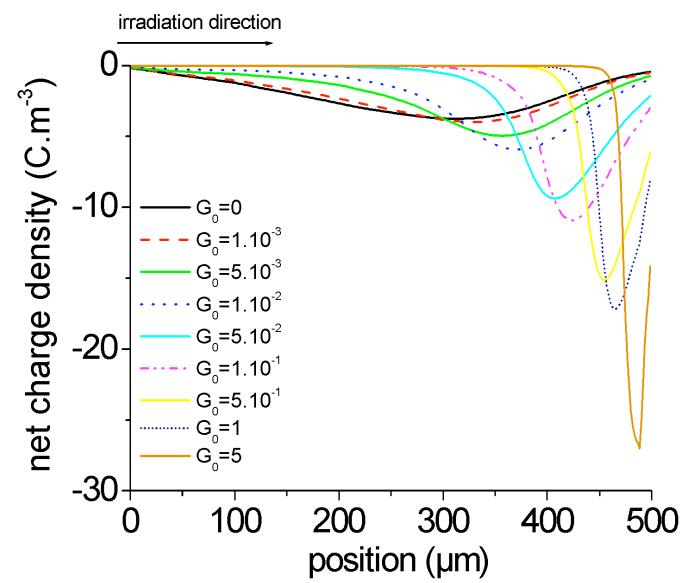

Figure 7: Simulated net charge density vs. position in the dielectric for different values of the electron/ hole pair generation coefficient $\mathrm{G}_{0}$ and an irradiation time of $36 \mathrm{~min}$. Other parameters of the model as in table 1 .

Figure 8a) and b) show the density of mobile and trapped electrons and holes after 36 min of irradiation for $\mathrm{G}_{0}=10^{-3}$ and $5 \cdot 10^{-2} \mathrm{C} \cdot \mathrm{m}^{-3} \cdot \mathrm{s}^{-1}$. The densities of electrons and holes are a decade higher for $\mathrm{G}_{0}=5.10^{-2} \mathrm{C} \cdot \mathrm{m}^{-3} \cdot \mathrm{s}^{-1}$, even if the peak maximum on figure 7 only increases from -4 to $-9 \mathrm{C} . \mathrm{m}^{-3}$. The net charge density does not map the 'real' density of carriers inside the bulk. For low values of the pairs generation coefficient, the negative peak is mainly due to electron deposition and transport in the direction of the ground electrode under the own field of the generated carriers (figure 8c). For high $\mathrm{G}_{0}$, it must be realized that the net charge being measured is the result of the unbalance between local positive and negative carrier densities, the later being in fact much higher than the net charge. The shift of the charge peak to the ground electrode at high Go results from several processes:

- A higher residual field as one approaches the ground electrode and hence higher velocity of charges in that region

- An increase in the number of carrier pairs producing therefore a larger drift current and hence unbalance in positive/negative charge densities. 
Another feature to consider is that the charge state obtained after 36 min of irradiation actually does not represent a steady situation, neither in the quantity of deposited charge (no steady state achievable as the quantity of positive carriers will be linearly increasing with irradiation time as neither recombination nor extraction to the irradiated face are considered), nor in the position of the charge peak since the extraction flux is still lower than the incoming flux due to the source term.

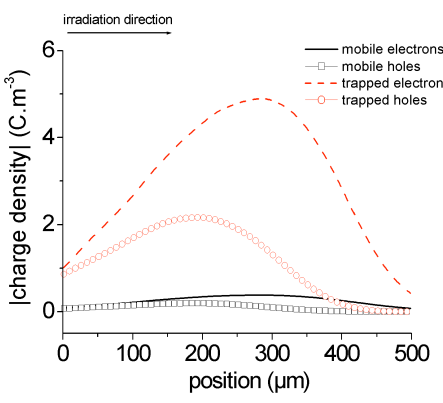

a)

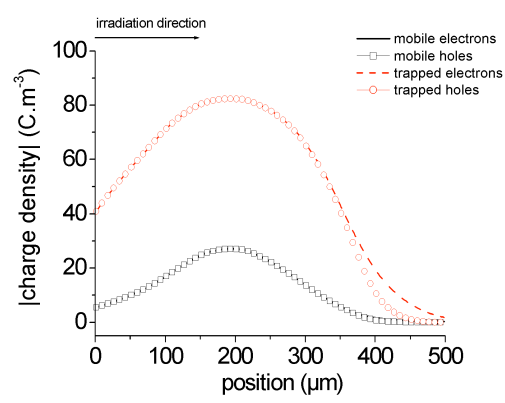

b)

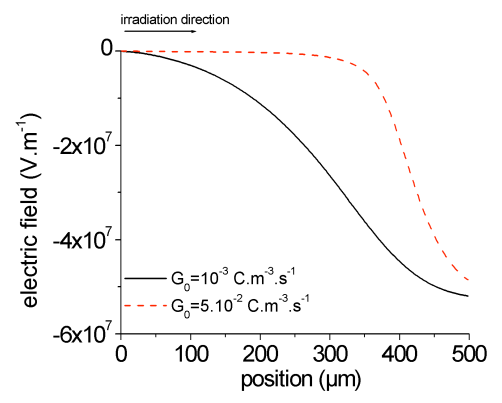

c)

Figure 8: Charge densities of mobile and trapped electrons and holes vs. position in the dielectric after 36 min of irradiation for a) $\mathrm{G}_{0}=10^{-3}$ and b) $\mathrm{G}_{0}=5 \cdot 10^{-2} \mathrm{C} \cdot \mathrm{m}^{-3} \cdot \mathrm{s}^{-1}$. c) electric field vs. position in the sample for $\mathrm{G}_{0}=10^{-3}$ and $\mathrm{G}_{0}=5.10^{-2} \mathrm{C} \cdot \mathrm{m}^{-3} \cdot \mathrm{s}^{-1}$ after $36 \mathrm{~min}$ of irradiation. Other parameters as in table 1 .

\subsubsection{Recombination coefficients}

Simulated results obtained for the different recombination coefficients are given in figure 9 after 36 min of irradiation. $\mathrm{G}_{0}$ has been set to $10^{-2} \mathrm{C} \cdot \mathrm{m}^{-3} \cdot \mathrm{s}^{-1}$ (a reasonable value on the basis of the experimental results) and the recombination coefficients for a given mechanism to $5.10^{-1} \mathrm{~m}^{3} \cdot \mathrm{s}^{-1} \cdot \mathrm{C}^{-1}$. The curve for $\mathrm{G}_{0}=0$ is given as a reference. Other parameters are given in table 1 .

The recombination between trapped charges (coefficient $\mathrm{S}_{0}$ ) seems to have a small impact on the net charge density, as the distribution of charge is almost the same as the one without recombination. On the contrary, recombination between mobile charges (coefficient $S_{3}$ ) is critical with a resulting net charge density equivalent to a charge distribution without pair generation $\left(\mathrm{G}_{0}=0\right)$. Recombination between mobile charges completely neutralizes the pairs generated by the irradiation and the net charge density is almost identical as the one derived from the unipolar case (cf. § 4.2.)

Recombination between mobile charge of one kind with the trapped charge of the opposite sign (coefficients $S_{1}$ and $S_{2}$ ) also changes the charge distribution, making transport to the non-irradiated region less effective and hence diminishing the charge density peak at $\approx 380 \mu \mathrm{m}$.

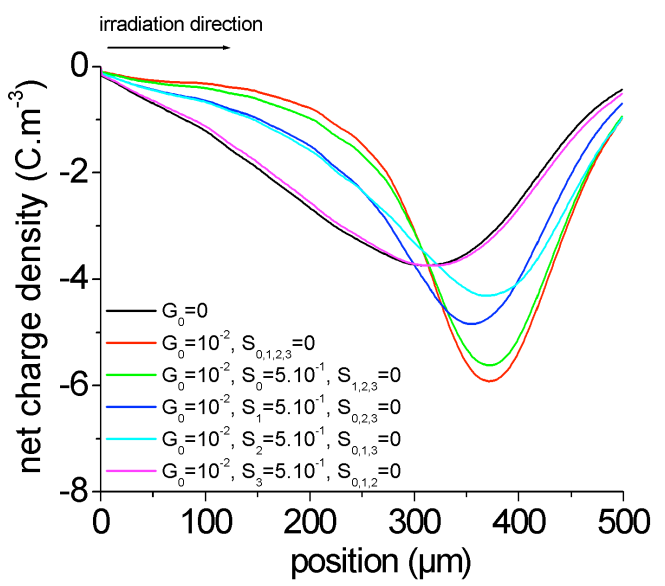

Figure 9: Simulated net charge density vs. position in the dielectric for different values of the recombination coefficients S. Irradiation time $36 \mathrm{~min} ; \mathrm{G}_{0}=10^{-2} \mathrm{C} \cdot \mathrm{m}^{-3} \cdot \mathrm{s}^{-1}$. Other parameters of the model as in table 1.

Recombination processes have therefore a large impact on the net charge distribution when taking recombination coefficient in the range $5.10^{-1} \mathrm{C}^{-1} \cdot \mathrm{m}^{3} \cdot \mathrm{s}^{-1}$. This result may appear contradictory with what had been concluded in [23] where the impact of recombination was not evidenced (considering recombination coefficient in the range $10^{-1}$ to $10^{-5}$ ) in charge transport in LDPE under a DC field. 
However, results can be reconciliated when considering that the number of recombination events per unit time depends on the charge density of each kind of carrier that recombines. Taking the actual numbers for recombining events, one get about $10^{+2}$ to $10^{+3} \mathrm{C} \cdot \mathrm{m}^{-3} \cdot \mathrm{s}^{-1}$ (peak densities of figure $8 \mathrm{~b}$ ) for recombination processes involving mobile charges with mobile or trapped charges of opposite polarity. Charge density is much less when considering charge transport in LDPE at low field value, in the range 1 to $10 \mathrm{C} \cdot \mathrm{m}^{-3}$, leading to a number of recombining events of about $10^{-1}$ to $10 \mathrm{C} \cdot \mathrm{m}^{-3} \cdot \mathrm{s}^{-1}$ (for the same recombination coefficient). In another work [24], recombination processes were shown to control the shape of the current-voltage characteristic in LDPE at high field where charge density reaches values in the same range as the irradiation case $\left(10\right.$ to $\left.10^{+2} \mathrm{C} \cdot \mathrm{m}^{-3} \mathrm{~s}^{-1}\right)$.

Recombination coefficients are therefore of prime importance in the current conditions and must be considered carefully. Given the shape of the obtained profiles, it is however difficult to balance the relative values of these coefficients as they all induce the same trends on the net charge profiles. For optimization purpose with a non-empirical evaluation of those parameters, it becomes therefore necessary to consider Langevin coefficients for recombination involving mobile species (mobilitydependent coefficients) and the average inter-trap distance for recombination between trapped species.

\section{Experiment vs. simulation}

\subsection{Post-treatment of the simulated space charge profiles}

Outputs of the model cannot be directly compared to space charge profiles obtained by PEA measurements because of the existence of image charges on the electrodes inherent to the measurement technique. To account for image charges, surface charge densities have been added at the electrodes in the simulated results [10]. Secondly, space charge profiles obtained by the PEA method, as well as with other technique, are obtained with a limited spatial resolution, which is characteristic of the experimental set-up. This results from a combination of the width of the excitation pulse, of the bandwidth of the piezoelectric sensor, the related amplifier and the oscilloscope, and of filtering of the signal during its processing. As a result, capacitive charges measured on a space-charge free material under voltage appear as Gaussian curves on the charge distribution profile instead of a Dirac distribution. As it is not possible in practice to correct experimental data for the spatial resolution of the set-up, we have applied a numerical filter to our data in order to loose part of the resolution reached by the simulated profiles. This was done by converting the profile into the frequency domain, applying a Gaussian filter, and then inverting again by FFT (Fast Fourier Transform).

\subsection{Comparison between experiments and simulation results}

Figure 10 shows (a) the experimental and (b) the simulated space charge profiles for different irradiation times. As already pointed out, the optimized transport parameters have been taken from [10]. Other parameters $\left(\mathrm{G}_{0}\right.$ and $\left.\mathrm{S}_{\mathrm{i}}\right)$ have been adapted with the help of the sensitivity analysis so as to better fit the experimental results. Only injection barrier height for holes at the ground electrode had to be found, as the metal electrode (Al) is different of the one used for LDPE under DC stress (gold). It has been chosen as to better fit the experimental profile. The set of optimized parameters is given in table 2 .

The experimental charge profiles show the fast apparition $(2 \mathrm{~min})$ of a negative peak of charge at around $320 \mu \mathrm{m}$ from the irradiated electrode. The peak shifts with the irradiation time towards the ground electrode and increases in amplitude up to $24 \mathrm{~min}$. Then it stabilizes at about $370 \mu \mathrm{m}$ and its amplitude does not increase any more until irradiation is stopped $(36 \mathrm{~min})$. Charges detected near the irradiated surface is very low and could be due to the existence of electrons with energy $<200 \mathrm{keV}$ in the impinging beam as discussed by Perrin et al. [5]. The same authors explain the stabilization in the negative charge peak amplitude by electron extraction and positive charge injection from the grounded electrode (equilibrium between charge deposition by the irradiation beam and charge release through the electrode).

In comparison, the model is able to reproduce the majority of the characteristics highlighted in the experiment. The simulated profiles show the appearance of a negative peak centred at $320 \mu \mathrm{m}$ after 2 minutes of irradiation, shifting towards the ground electrode and stabilizing at $380 \mu \mathrm{m}$. The net charge density is higher in the simulations compared to the experimental one by a factor 2 . At $t=36 \mathrm{~min}$, the remaining charge measured is around $5.10^{-4} \mathrm{C} . \mathrm{m}^{-2}$ (integral of the charge peak), much less than the 
Table 2: Optimized parameterization of the bipolar model for the simulation of space charge in an irradiated LDPE. Parameters of the transport model are taken from [10].

\begin{tabular}{|c|c|c|}
\hline Symbol & Value & Units \\
\hline $\begin{array}{l}\text { Trapping coefficient } \\
B_{\mathrm{e}} \text { electrons } \\
B_{h} \text { holes }\end{array}$ & $\begin{array}{l}0.10 \\
0.20\end{array}$ & $\begin{array}{l}\mathrm{s}^{-1} \\
\mathrm{~s}^{-1}\end{array}$ \\
\hline $\begin{array}{l}\text { Mobility } \\
\text { Electrons } \\
\text { holes }\end{array}$ & $\begin{array}{l}\text { 1. } 10^{-14} \\
\text { 2. } 10^{-13}\end{array}$ & $\begin{array}{l}\mathrm{m}^{2} \mathrm{~V}^{-1} \mathrm{~s}^{-1} \\
\mathrm{~m}^{2} \mathrm{~V}^{-1} \mathrm{~s}^{-1}\end{array}$ \\
\hline $\begin{array}{l}\text { Deep trap density } \\
N_{\text {oet }} \text { for electrons } \\
N_{\text {oht }} \text { for holes }\end{array}$ & $\begin{array}{l}100 \\
100\end{array}$ & $\begin{array}{l}\mathrm{C} \mathrm{m}^{-3} \\
\mathrm{C} \mathrm{m}^{-3}\end{array}$ \\
\hline $\begin{array}{l}\text { Schottky injection barrier } \\
\mathrm{W}_{\text {ei }} \text { for electrons } \\
\mathrm{W}_{\text {hi }} \text { for holes }\end{array}$ & $\begin{array}{l}1.27 \\
1.3 \\
\end{array}$ & $\begin{array}{l}\mathrm{eV} \\
\mathrm{eV}\end{array}$ \\
\hline $\begin{array}{l}\text { Detrapping barrier height } \\
\mathrm{w}_{\text {tre }} \text { for electrons } \\
\mathrm{W}_{\text {trh }} \text { for holes }\end{array}$ & $\begin{array}{l}0.96 \\
0.99\end{array}$ & $\begin{array}{l}\mathrm{eV} \\
\mathrm{eV}\end{array}$ \\
\hline $\begin{array}{l}\text { Recombination coefficients } \\
S_{0} \\
S_{1} \\
S_{2} \\
S_{3}\end{array}$ & $\begin{array}{l}1.10^{-1} \\
5.10^{-1} \\
1.10^{-2} \\
1.10^{-1}\end{array}$ & $\begin{array}{l}\mathrm{m}^{3} \cdot \mathrm{s}^{-1} \cdot \mathrm{C}^{-1} \\
\mathrm{~m}^{3} \cdot \mathrm{s}^{-1} \cdot \mathrm{C}^{-1} \\
\mathrm{~m}^{3} \cdot \mathrm{s}^{-1} \cdot \mathrm{C}^{-1} \\
\mathrm{~m}^{3} \cdot \mathrm{s}^{-1} \cdot \mathrm{C}^{-1}\end{array}$ \\
\hline $\begin{array}{l}\text { Electron / hole pair generation coefficient } \\
\mathrm{G}_{0}\end{array}$ & 5. $10^{-2}$ & $\mathrm{C} \mathrm{m}^{-3} \cdot \mathrm{s}^{-1}$ \\
\hline
\end{tabular}

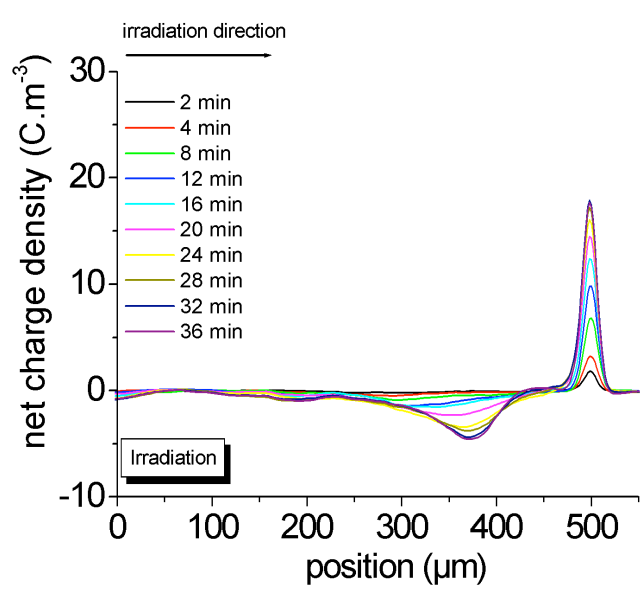

a)

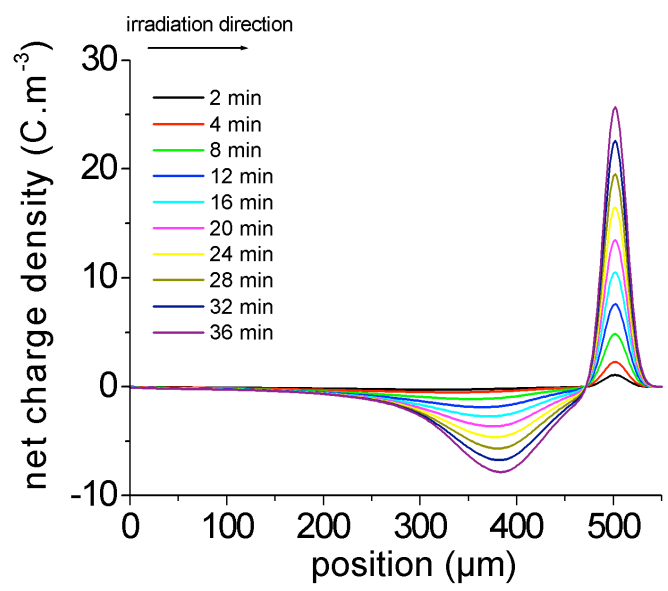

b)

Figure 10: Space charge profiles for a $500 \mu \mathrm{m}$ LDPE in 'Open-circuit' configuration during 36 min of irradiation with a $200 \mathrm{keV}$ electron beam, obtained a) experimentally (PEA method -from [5] with the permission of the authors) and $b$ ) with the simulation (parameters of table 2).

simulated charge which is roughly equal to the injected charge $\left(1.10^{-3} \mathrm{C} . \mathrm{m}^{-2}\right.$ for an irradiation flux of $50 \mathrm{pA} . \mathrm{cm}^{-2}$ during $36 \mathrm{~min}$ ). It seems therefore that simulation underestimates charge extraction from the grounded electrode and/or positive charge injection from the same electrode, which would compensate (or recombine) part of the negative charge. Other possibilities are directly linked to the experimental procedure, i.e. the irradiation flux being not exactly of $50 \mathrm{pA} . \mathrm{cm}^{-2}$.

The amount of positive charge in the dielectric at the end of the irradiation is quite small (figure 11). Most of the positive charges in the region 300 to $500 \mu \mathrm{m}$ have been recombined whereas they still exist in the region from the irradiated surface to $300 \mu \mathrm{m}$. It is also possible to see on figure 11.a) that the density of holes is higher than the density of electrons at the vicinity of the ground electrode, due to the injection of positive charges at this electrode. However, this is less observable on figure 10 where image charges have been added. 


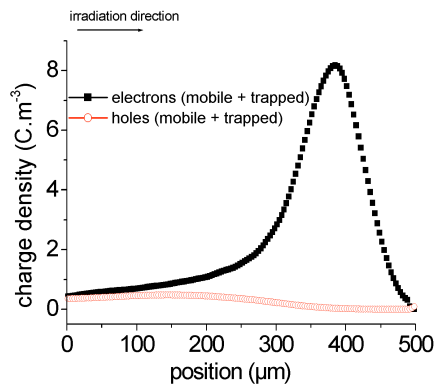

a)

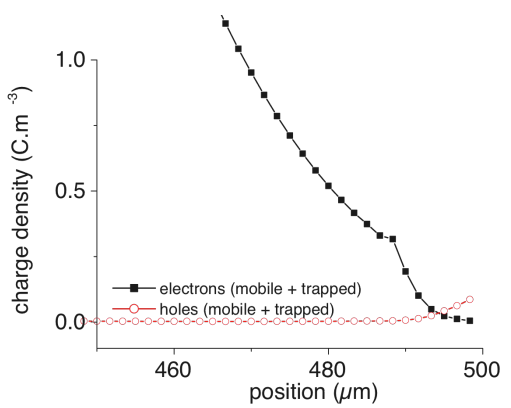

b)

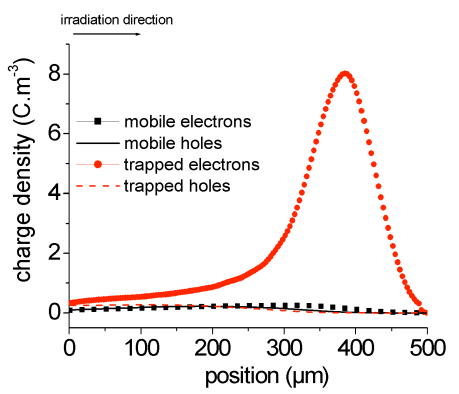

c)

Figure 11: a) Cumulative positive and negative charges b) zoom of the cumulative charge in the region 450-500 $\mu \mathrm{m}$, and c) charge densities of the different carriers vs. position in the dielectric after 36 min of irradiation.

Profiles do not take into account the image charges. Parameters of table 2.

Summarizing the results, the main points of interest that come out from this study are the following: (i)-a bipolar approach seems appropriate in modelling electron beam irradiated dielectrics. It allows to describe, at least qualitatively, all the features revealed by the experiments; (ii)-the field distribution (see figure 12) leads to negative charge transport towards the grounded electrode where they are evacuated. In the same time, positive charge injection takes place as evidenced in simulation and in experiments. A balance between these two processes should lead to a zero charge region, evidenced in experiments, but the effect seems to be underestimated by the simulation; (iii)-electron/hole pairs generation and recombination process are two important phenomena that control the space charge distribution under electron beam irradiation. The correct parameterization of these processes is probably a key to fit the RIC and delayed RIC observed in experiments; (iv)-recombination involving mobile carriers is the most efficient process, the less operant being recombination involving trapped charges.

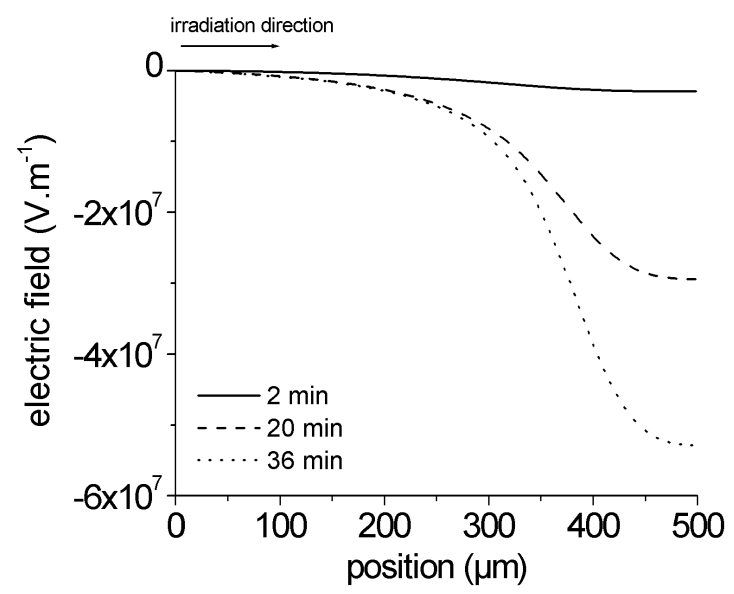

Figure 12: Electric field vs. position in the dielectric for different times under irradiation. Parameters of table 2. Profiles do not take into account the image charges.

\section{Conclusion}

Simulations of space charge accumulation in electron irradiated low density polyethylene have been done by combining a deposition model taking into account the generation of electron/hole pairs and a bi-polar transport model developed for charge transport in LDPE under electrical stress. Parameterization of the deposition model has been done on the basis of a sensitivity analysis concerning electron/hole pairs generation and recombination coefficients, plus consideration of the experimental charge distribution. Optimized parameters of the transport model have been kept from the literature work. The model is able to reproduce most of the features observed experimentally although the global optimization has to be improved. The next step in the model development will be to find an optimized set of parameters for all the experimental data available for LDPE, i.e. space charge measurements under irradiation and during relaxation for the 'open-circuit' and the 'short- 
circuit' configuration where the irradiated surface of samples is either at a floating potential or grounded.

\section{Acknowledgments}

The authors would like to acknowledge the Centre National d'Etudes Spatiales (CNES) in Toulouse and particularly Dr. D. Payan for lively discussion and financial support. Authors would also like to acknowledge the ONERA/DESP, as experiments have been performed in the SIRENE facility. We also would like to thank C. Inguimbert from ONERA/DESP for GEANT4 simulations.

\section{References}

[1] Catani J P and Payan D 2004 Proc. Int. Conf. Solid Dielectrics, (Toulouse, France) 2 917-27

[2] Gross B, Sessler G M and West J E 1974 J. Appl. Phys. 45 2841-51

[3] Sessler G M, Gerhard-Multhaupt R, Von Seggorn H and West J E 1986 IEEE Trans. Electr. Insul. 21 411-5

[4] Griseri V, Perrin C, Fukunaga K, Payan D, Lévy L and Laurent C 2006 IEEE Trans. Plasma Sci. 34 2185-90

[5] Perrin C, Griseri V, Inguimbert C and Laurent C 2008 J. Phys. D : Appl. Phys. 41205417

[6] Leal Ferreira G F and De Figueiredo M T 2003 IEEE Trans. Dielectr. Electr. Insul. 10 137-47

[7] Sessler G M, De Figueiredo M T and Leal Ferreira G F 2004 IEEE Trans. Dielectr. Electr. Insul. 11 192-202

[8] Inguimbert C, Carrere Y, Griseri V, Dirassen B, Levy L, Payan D and Fukunaga K 2004 Proc. Int. Conf. Solid Dielectrics (Toulouse, France) 2 951-4

[9] Touzin M, Goeuriot D, Guerret-Piécourt C, Juvé D, Tréheux D and Fitting H J 2006 J. Appl. Phys. 99114110

[10] Le Roy S, Teyssedre G, Laurent C, Montanari G C and Palmieri F 2006 J. Phys. D: Appl. Phys. 39 1427-36

[11] Sessler G M 1992 IEEE Trans. Electr. Insul. 27 961-73

[12] Maeno T, Futami T, Kushibe H and Takada T 1989 J. Appl. Phys. 65 1147-51

[13] Kotera M, Yamagushi K and Hiroshi S 1999 Jpn J. Appl. Phys. 38 7176-9

[14] Labonte K 1982 IEEE Trans. Nucl. Sci. 29 1650-3

[15] Pine V W, Beers B L and Sherwood T I 1983 Trans. Nucl. Sci 30 4290-5

[16] Griseri V, Perrin C, Fukunaga K, Maeno T, Payan D, Dirassen B and Laurent C 2007 Proc. Conf. on Electrical Insulation and Dielectric Phenomena (Vancouver, Canada) 429-32

[17] Le Roy S, Baudoin F, Boudou L, Laurent C and Teyssedre G 2009 Proc. Conf. on Electrical Insulation and Dielectric Phenomena (Virginia Beach, USA) 154-7

[18] Boufayed F, Teyssedre G, Laurent C, Le Roy S, Dissado L A, Ségur P and Montanari G C 2006 J. Appl. Phys. 100104105

[19] Leonard B P 1979 Computer Methods in Applied Mechanics an Engineering 19 59-98

[20] Leonard B P 1991 Computer Methods in Applied Mechanics an Engineering 88 17-74

[21] Le Roy S , Teyssedre G and Laurent C 2006 IEEE Trans. Dielectr. Electr. Insul. 13 239-46

[22] http://geant4.web.cern.ch/geant4/

[23] Le Roy S, Teyssedre G, Segur P and Laurent C 2003 Proc. Int. Conf. on Properties and Applications of Dielectric Materials (Nagoya, Japan) 859-62

[24] Baudoin F, Le Roy S, Teyssedre G and Laurent C 2008 J. Phys. D : Appl. Phys. 41025306 